\title{
Sensors for Quality Control in Welding
}

\section{(Sensores para Controle da Qualidade em Soldagem)}

\author{
Sadek Crisóstomo Absi Alfaro ${ }^{1}$ \\ ${ }^{1}$ Universidade de Brasília, Departamento de Engenharia Mecânica, Brasília, DF, Brasil, sadek@unb.br
}

\begin{abstract}
The classical inspection methods used for detecting and finding disturbances in welding process are based on direct measurement of its parameters as arc voltage, welding current, wire feed speed, etc. Using these inspection methods implies sensors insertion around the welding process and its presence could alter the metallic transference behavior and consequently an uneven quality as well as it can increase the production cost. For reducing these implications is necessary using a non intrusive inspection method. In this paper we will show nonintrusive methods to the weld quality inspection. These methods are based on sensor fusion, the extraction of global information coming from the interrelation data given by each sensor that, for example, sensing the spectroscopy radiation emission, the acoustic sensing of the electrical arc, the infrared emissions indicating the heat content of the weld. Finally, the fusion data will be applied to a statistical control for detecting and finding welding disturbances. The results will show that sensor fusion could be used as a tool to measure indirectly the weld quality in the GMAW process.
\end{abstract}

Key-words: Quality Control in Welding, Spectroscopy, Acoustic sensing, Infrared emission, Sensor fusion.

Resumo: Os métodos clássicos de inspeção utilizados para detectar e encontrar perturbações nos processos de soldagem são baseados comumente na medição direta de seus parâmetros como da tensão do arco, corrente de soldagem, velocidade de alimentação, etc. Usando esses métodos de inspeção implica inserção dos sensores em todo o processo de soldagem e sua presença poderia alterar o comportamento, por exemplo, da transferência metálica e, consequentemente, uma qualidade irregular da junta soldada, bem como provocaria o aumento do custo de produção. Para reduzir essas implicações é necessário usar um método de inspeção não intrusiva. Neste artigo mostrar-se métodos não intrusivos para a inspeção de qualidade de solda. Estes métodos baseiam-se na fusão de sensores, a extração da informação global vinda dos dados fornecidos por cada sensor, como por exemplo, a detecção de emissão de radiação de luz pela espectroscopia, o sensoreamento acústico do arco eléctrico ou as emissões de infravermelho, correlacionando o insumo de calor do processo. Finalmente, a fusão de dados será aplicada a um controlo estatístico para detectar e encontrar perturbações no processo de soldagem. Os resultados mostram que a fusão de sensores pode ser utilizada como uma ferramenta para medir indiretamente a qualidade nos processos de soldagem, especificamente no processo GMAW.

Palavras-chave: Controle da qualidade em soldagem, Espectroscopia, Sensoreamento acústico, emissões infravermelhas, Fusão de sensores.

\section{Introduction}

The welding process is used by many manufacture companies and due to this wide application many studies have been carried out in order to improve the quality and to reduce the cost of welded components. Part of the overheads is employed in final inspection, which begins with visual inspection, followed by destructive and non-destructive testing techniques. In addition to cost raise, final inspection is conducted when the part is finished only. When a defect occurs during welding, it can be reflected in the physical phenomena involved: magnetic field, electric field, temperature, sound pressure, radiation emission and others. Thus, if a sensor monitor one of these phenomena, it

(Convidado em 15/05/2012; Texto final em 18/08/2012). is possible to build a system to monitor the weld quality.

For the automation and control of complex manufacturing systems, a great deal of progress came up in the last decade, with respect to precision and on-line documentation (bases for the quality control). With the advent of electrically driven mechanical manipulators and later the whole, relatively new, multidisciplinary mechatronic engineering, the need of information acquisition has increased. The acquisition is, in many cases, distributed through the system, with strong interaction between the robot and its environment. The design objective is to attain a flexible and lean production. The requirement of real time processing of data from multisensor systems with robustness, in industrial environment, shows the need for new concepts on system integration.

A Multisensor system represents neither the utilization of many sensors with the same physical nature nor many independent measurement systems, but mainly sensor fusion, the extraction of global information coming from the interrelation 
data given by each sensor. Some examples are the estimation of the slope of any surface using two or three individual sensors, the simultaneous acquisition of the parameters of the automatic welding process MIG/MAG ("Metal Inert Gas/ Metal Active Gas") or the direct observation of the welding pool related to the control of current, voltage, wire speed and torch welding speed.

Technology advancements seek to meet the demands for quality and performance through product improvements and cost reductions. An important area of research is the optimization of applications related to welding and the resultant cost reduction. The use of non-destructive tests and defect repair are slow processes. To avoid this, online monitoring and control of the welding process can favor the correction and reduction of many defects before the solidification of the melted/fused metal, reducing the production time and cost.

With continuing advancements in digital and sensor technology, new methods with relatively high accuracy and quick response time for identification of perturbations during the welding process have become possible. Arc position, part placement variations, surface contaminations and joint penetration are key variables that must be controlled to insure satisfactory weld production [1].

The techniques related to welding process optimization are based on experimental methodologies. These techniques are strongly related to experimental tests and seek to establish relations between the welding parameters and welding bead geometry. The introduction of close or adaptive control to welding processes must be done by monitoring a variable or set of variables which can identify a process disturbance. For each practical implementation of an adaptive system to a welding process one should identify the "envelope" or the set of monitoring variables. These variables must be used as a reference value in the process control, making the system control start with a parameter adjustment (welding current, voltage, etc.) to guarantee bead characteristics close to desirable values. The welding parameters vary in accordance to base material, type of chosen process, plate dimensions and welding bead geometry, so the adjustment of the reference value of a monitored variable will depend on the establishment of a set of optimized parameters which provide a welding bead with desirable specifications.

Researches related to adaptive systems for welding seek the improvement of welding bead geometry with direct (if based on monitoring sensors) or indirect monitoring techniques. The indirect monitoring systems are the more used, looking to link elements such as welding pool vibrations, superficial temperature distribution and acoustic emissions to size, geometry or welding pool depth [2]. The most used approaches in welding control are infrared monitoring, acoustic monitoring, welding pool vibrations and welding pool depression monitoring [3].

Aiming to optimize human analysis during the defect identification process, many researches were conducted to develop alternative techniques for automatic identification of defects considering different classes of signals such as plasma spectrum [4], ultrasonic [5], computer vision [6], etc.

Three levels of "on-line" quality control have been adopted by the industry (see Fig. 1). In the first level, it should be able to automatically detect "on-line" bad welding joint production. In the second level, it should be able to search and to identify the fault and which are the reasons for the fault occurrence (changes in welding process induced by disturbances in shielding gas

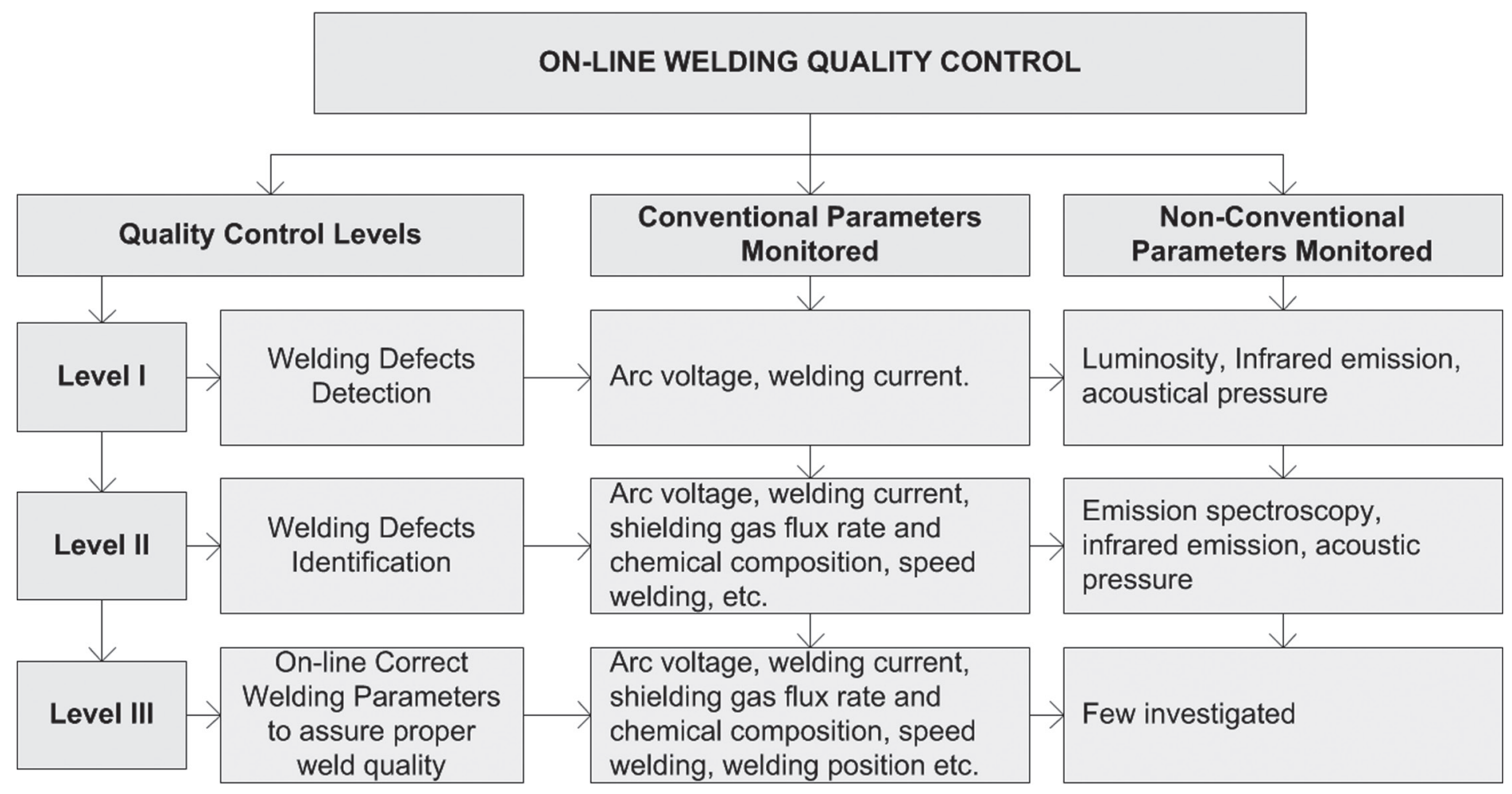

Figure 1. On-line Welding Quality Control Levels. 
delivery, changes in wire feed rate and welding geometry, etc). In the third level, it should be able to correct welding parameters during the welding process to assure proper weld quality [7]. The conventional parameters are usually used to detect and to identify defects. Moreover, the non-conventional parameters, at the present, are not used enough to evaluate the welding quality. They are some non-contact methods for welding monitoring process as acoustical sensing [8-15], spectroscopy emission [1618], infrared emission [19-21] and sensoring combination [22].

\section{Sensors in welding}

\subsection{Spectroscopy}

The science responsible for the study of the radiation emission is called spectroscopy. The physical phenomena consist on a photon emission in a determined wavelength or frequency after the absorption of some energy. Atoms, ions and molecules can emit photons in different wavelengths, but a wavelength is related only to one atom or ion or molecule. This can be compared to a fingerprint. Thus, with this property it is possible to know what chemical element, ion or molecule is found at the reading area.

It is possible to improve a non-destructive and on-line weld defects monitoring system through the radiation emitted by the plasma present in the electric arc. Some spectral lines involved in the welding process are chosen and their intensity is measured by a spectrometer sensor. One objective is to evaluate whether the spectrometer is capable of sensing disturbances in the electric arc. Another goal is to determine change detection techniques able to point those disturbances.

Two analyses can be made with this information: qualitative and quantitative. In a qualitative approach, one is concerned in what elements are found on the plasma. And as a quantitative study, the objective is to evaluate some information extracted by the spectral taken. Therefore, a spectrometer could be applied as a sensor in a manufacturing process, such as welding, to detect the presence of some chosen elements or substances, like Iron, Cooper, water, grease; or to monitor significant changes of the energy emitted by some elements.

For example, in a stable GTAW the spectrum of the electric arc is stable as well. The amount of shielding gas, vaporized and melted steel, and other elements found at the electric arc are quite constant; therefore, if reflects on a stable spectrum. If a quantity of any element changes it will reflect on higher or lower emission energy. If different elements are introduced on the process, it will raise the energy of those elements.

An ordinary factor applied as a quantitative evaluation is the calculation of the plasma Electronic Temperature. Another that can be applied is the intensity of radiation emitted by some spectral lines. The Electronic Temperature can be calculated with different techniques, one is the relative intensity of spectral lines, of the transition from the level $\mathrm{m}$ to $\mathrm{r}$ of one line and from $\mathrm{j}$ to $\mathrm{i}$ of the other line, given by Equation 1 [23].

$$
T_{e}=\frac{E_{m}-E_{j}}{K_{B} \cdot \mathrm{h}\left(\frac{E_{m} \cdot I_{j} \cdot A_{m} \cdot g_{m} \cdot \lambda_{j}}{E_{j} \cdot I_{m} \cdot A_{j} \cdot g_{j} \cdot \lambda_{m}}\right)}
$$

Where: $\mathrm{E}$ is the energy level, $\mathrm{KB}$ is the Boltzmann constant, $\mathrm{I}$ is the spectral line intensity, $\mathrm{A}$ is the transition probability, $\mathrm{g}$ is the statistical weight and $\lambda$ is the wavelength. These values can be found at the [24], except for the intensity, given by the sensor.

\subsection{Infrared emission}

Infrared emission is originated by the electromagnetic energy emitted by the welding arc and sensed just at infrared wavelength $(0.8-1.1$ specified in the pyrometer datasheet). Its intensity and wavelength of energy produced depends on the welding parameters, electrode and base metal composition as well as fluxes of shielding gas. The intensity of this electromagnetic emission is governed by Planck's law which describes the spectral radiance of unpolarized electromagnetic radiation at all wavelengths emitted from a black body at absolute temperature. As a function of frequency, Planck's law is written as:

$I_{\mathrm{e}}(\mathrm{v}, \mathrm{T})=\frac{2 \mathrm{hv} \mathrm{v}^{3}}{\mathrm{c}^{2}} \frac{1}{\left[\frac{\mathrm{hv}}{\mathrm{kT}]}-1\right.}$

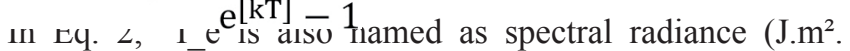
$\left.\mathrm{sr}^{-1}\right)$, $\mathrm{T}$ temperature $(\mathrm{K}), \mathrm{v}$ frequency $(\mathrm{Hz}), \mathrm{h}$ Plank constant $(6.62606896(33) \times 10-34 \mathrm{~J} . \mathrm{s})$, c speed of light $(3.0 \times 108 \mathrm{~m} / \mathrm{s})$ and $\mathrm{k}$ Boltzmann constant $(\approx 1.3806504) \times 10-23 \mathrm{~J} / \mathrm{K})$.

\subsection{Sound emission}

In GMAW-Short circuit (GNAW-S) process, the metal is transferred to the welding pool when the molten tip of the consumable electrode contacts the molten puddle. This generates sudden changes in the power of the welding arc. In GMAW-S, the welding arc is characterized by ignitions and extinction sequences and the welding arc sound fits this welding arc behavior. In each arc ignition there is a sound peak as well as when the arc has been extinct, a small sound peak is produced. Also is noticed that there is a delay in the sound compared with the arc voltage. This delay is produced by the airborne nature of the sound and its value is not great than $400 \mathrm{~ms}$, which means that the welding arc sound, is feasible for getting reliable information from welding arc [25]. The correspondence between the welding arc sound emission and the welding arc power could be expressed by Eq. 3 [26].

$\mathrm{S}_{\mathrm{e}}(\mathrm{t}) \approx \mathrm{K}\left[\frac{\mathrm{d}(\mathrm{P}(\mathrm{t}))}{\mathrm{dt}}\right]$

$\alpha(\gamma-1) / c^{2}$

wnere: $\mathbf{K}$ is a proportionality factor, is a geometrical factor, the adiabatic expansion coefficient of air and the velocity of sound in the arc. 


\section{Sensors for Quality Control in Welding}

\section{Arc welding emissions}

\subsection{Stationarity of arc emissions}

Stationarity is a statistical property of random nature signals which means that the statistical quantities are independent of the absolute time and dependant only on relative times, in other words a signal is stationarity when its essential statistical properties are invariant over time. Two kinds of stationarity are distinguished: weak and strong stationarity. Weak stationarity is meant when the first and second moments are independent of time and constants, that is, and, (where stands for the ensemble average). For finite random signals that is the case of the welding arc emissions, the behaviour of the mean value and variance cannot be enough estimators for stationary. A stochastic process with as an integer number, is denominated as strongly stationary if any set of times and any integer the joint probability distributions of and coincide, in other words, when there is correlation between both distributions. Before to calculate the autocorrelation function is necessary obtain some statistical parameters considering each arc emission as a stochastic variable.

Probability average:

$\langle E\rangle_{j}=\lim _{N \rightarrow \infty} \frac{1}{N}\left[\sum_{i=1}^{N} E\left(\beta_{i}, \tau_{j}\right)\right]$

$\mathrm{j}=1,2, \ldots, M+1$

Where: is the number of realizations of the process is the number of time steps and is the random variable.

Time Average:

$\bar{E}=\lim _{T \rightarrow \infty} \frac{1}{2 T} \int_{0}^{T} E(t) d t$

Fluctuations:

$E^{\prime}(t)=E(t)-\bar{E}$

Since $\overline{E^{\prime}(t)}=0$, the variance is simply calculated as: $\sigma_{S^{\prime}}^{2}=\overline{E^{\prime 2}}$

The time average of the square of the fluctuations is evaluated by using the equation (8).

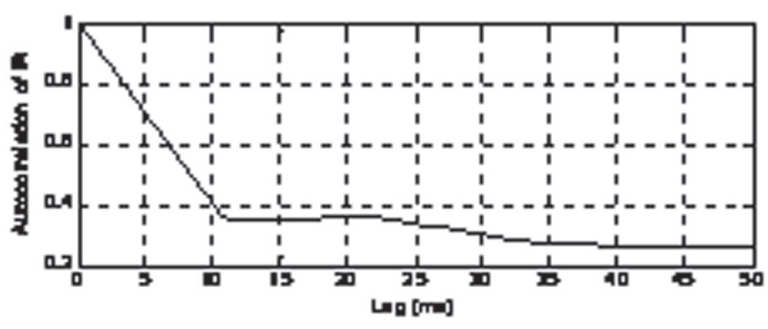

a) Sound

$$
\overline{\mathrm{E}^{\prime 2}}=\lim _{\mathrm{T} \rightarrow \infty} \frac{1}{\mathrm{~N}} \int_{0}^{\mathrm{T}} \mathrm{E}^{\prime 2}(\mathrm{t}) \mathrm{dt} \text {....lation is defined as: }
$$

$R_{E^{\prime}}(\tau)=\left\langle E^{\prime}(t+\tau) E^{\prime}(t)\right\rangle=\overline{E^{\prime}(t+\tau) E^{\prime}(t)}$

It is more convenient to work with the normalized autocorrelation function defined in equation (10). Note that indicates weak stationarity and indicates strong stationarity

$$
\operatorname{ACF}_{\mathrm{E}^{\prime}}(\tau)=\frac{\mathrm{R}_{\mathrm{E}^{\prime}}(\tau)}{\sqrt{\overline{\mathrm{E}^{\prime 2}(\mathrm{t})}} \sqrt{\mathrm{E}^{\prime 2}(\mathrm{t}+\tau)}}
$$
strong stationarity. Figures 2.a and 2.b display the plots of the normalized autocorrelation of sound and infrared emissions respectively.

Generally, the autocorrelation is expected to decay exponentially, and the fluctuations are expected to become uncorrelated after a sufficiently long-time. In the Fig. 2.a and 2.b are shown autocorrelation of infrared and sound emissions respectively. In these figures are observed that autocorrelation functions tend to zero which means that both welding arc emissions have a strong stationarity after certain time and therefore they can be used as welding monitoring parameters.

\subsection{Features extracted from arc emissions}

The geometrical uniformity is consequence of the welding stability. In GMAW-S, a high stability level is reached after taking some qualitative considerations such as when the pool fusion oscillation and SCR (Short Circuit Rate) are the same [27] or when there is balance between WFS (Wire feeed speed) and the melting rate [28]. These considerations are achieved when there is a: maximum SCR, minimal standard deviation of the SCR, minimal mass transfer in each short circuit and minimal spatter level [29]. Considering this requirements, from the infrared emission an infrared level indicator () was extracted (see Fig. 3.a) and from the welding arc sound emission, SCR was extracted. The envelope of welding arc sound was obtained by squaring and low-pass filtering processes. Finally the SCR was calculated by windowing and threshold process stages (see Fig. 3.b). In both graphs, the extracted parameters are related to welding arc power.

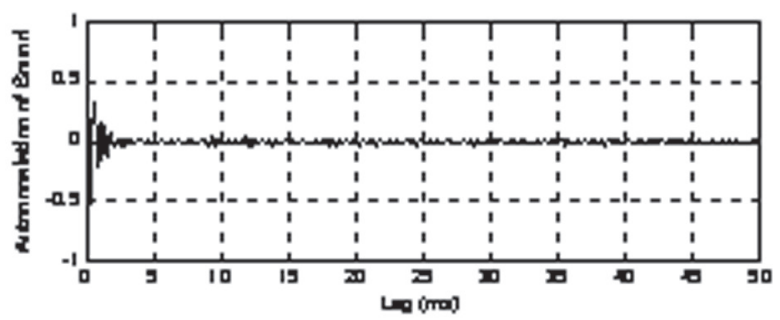

b) Infrared

Figure 2. Welding arc emissions autocorrelation. 


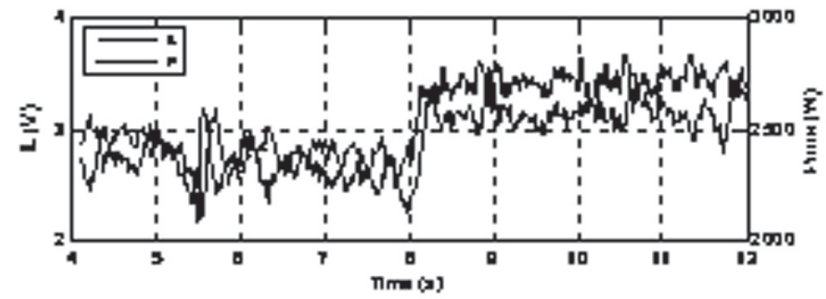

(a) infrared level indicator

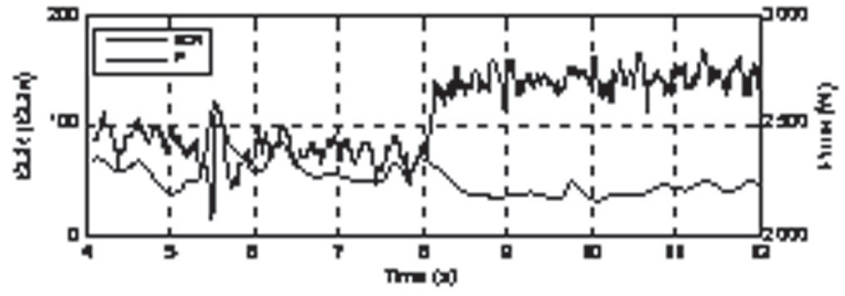

(b) Short circuit rate

Figure 3. Welding arc emissions autocorrelation.

\subsection{Relationship between welding arc emissions}

Figure 4 shows the relationship between the infrared level and the SCR for $7 \mathrm{~mm} / \mathrm{s}$ of welding speed and from this figure is noticed that there is an inverse relationship between them. It is noticed that when the arc voltage is greater, the infrared level is also greater as well as when the arc voltage is held constant and the WFS is increased the infrared level and the SCR increase but not necessarily the dept penetrations increase as it was explained above.

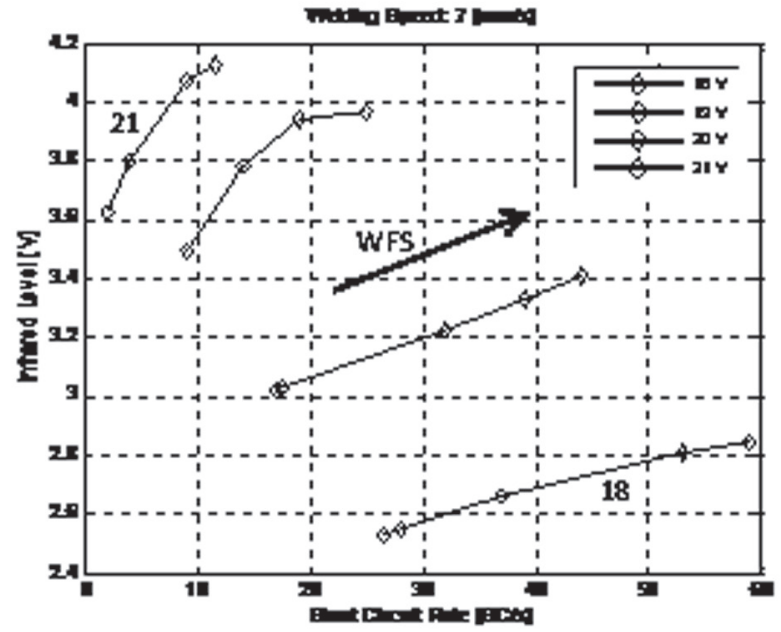

Figure 4. Relationships between arc emissions.

\section{Data Fusion}

Data fusion is the process of combining and integrating measured features originated from different sensors to produce a more specific, comprehensive, and unified information about monitored process such as the arc welding features in the case of this paper. There are different data fusion methods and one of them is the Kalman Filter-KF. In KF fusion method there are two broad approaches: measurement fusion and state-vector fusion. State-vector fusion is preferable in such practical situations [30]. In such a system, each sensor uses an estimator that obtains an estimate of the state vector and its associated covariance matrices from the data of that associated emission sensor. Then these state vectors are transmitted over a data link to the fusion center. As shown in Figure 5, state-vector fusion methods use a group of Kalman filters to obtain individual sensor-based state estimates which are then fused to obtain an improved joint state estimate. The KF is given for each set of observations, meaning that the algorithm is applied independently for each sensor (data) and generates state estimates. Figure 5 shows the overall data fusion architecture.

\section{Experimental setup}

Signals of acoustic and infrared emissions were sensored by a decibel meter B\&K 2250 and the pyrometer TL-S- 25 respectively. The decibel meter uses a 4189 type microphone

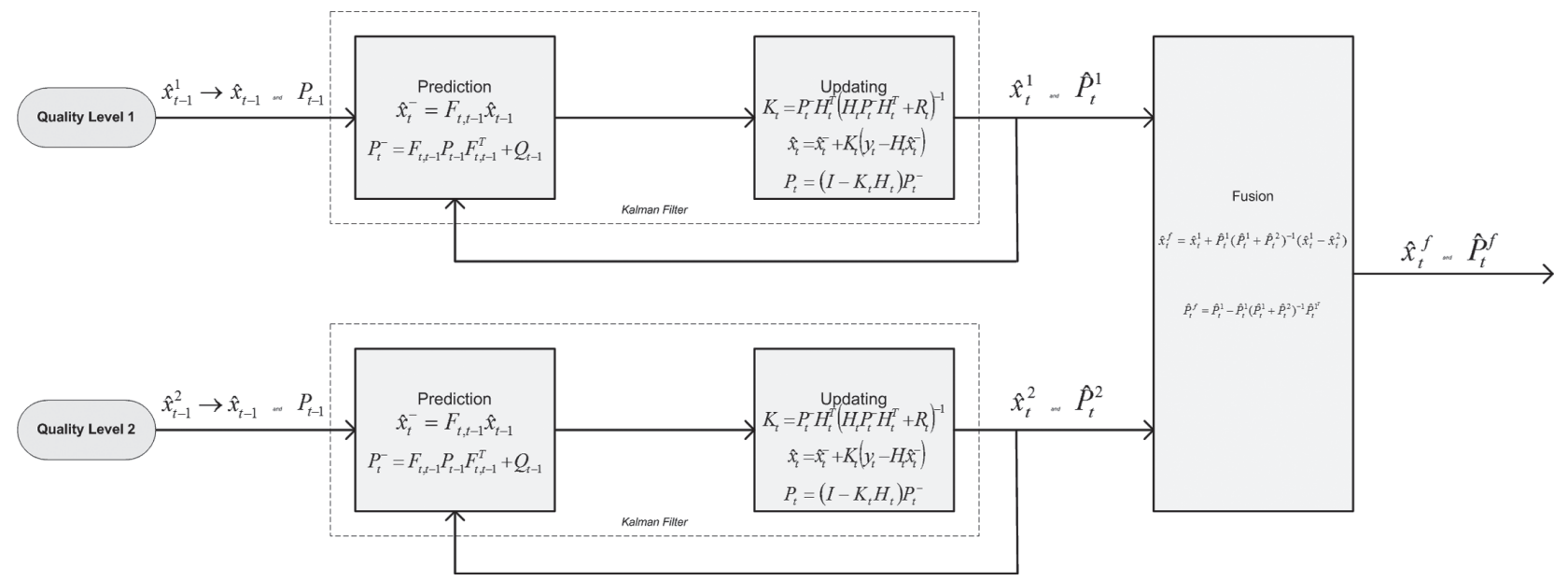

Figure 5. Detailed data fusion architecture. 


\section{Sensors for Quality Control in Welding}

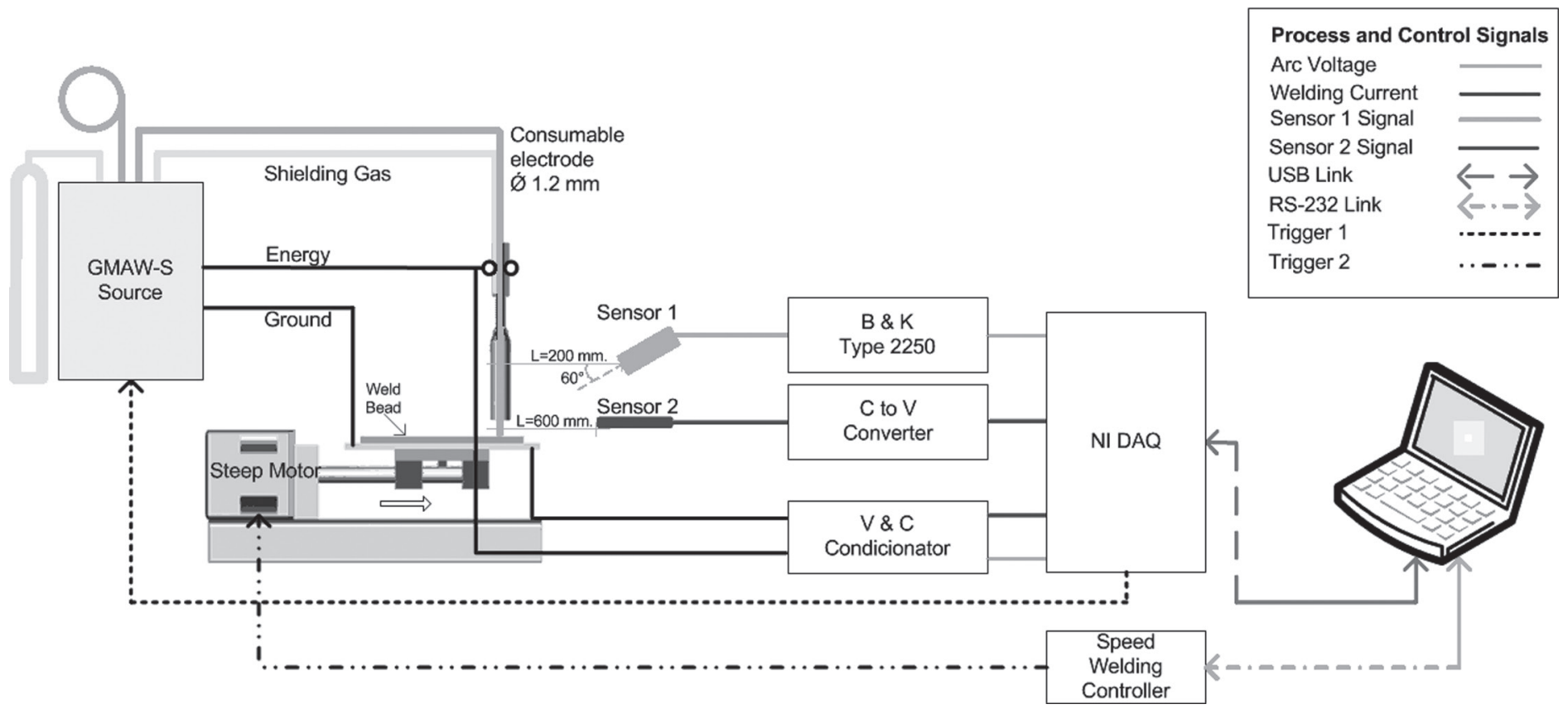

Figure 6. Experimental setup.

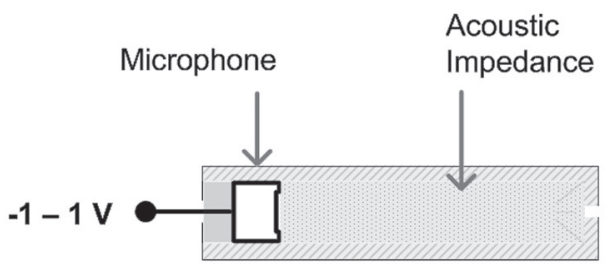

Sensor 1: Type 4189

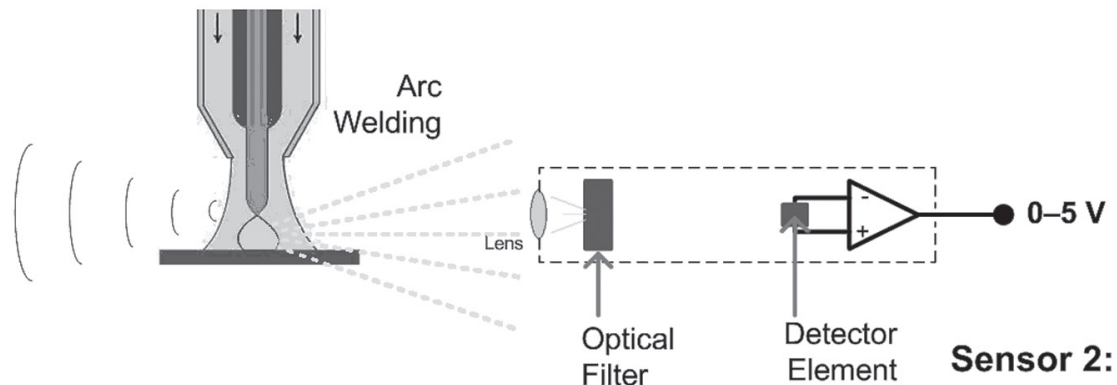

Filter
Element

Figure 7. Competitive topology.

with $-26 \pm 1.5 \mathrm{~dB}$ gain, $\pm 1.0 \mathrm{~V}$. output amplitude signal and sensitivity of $50 \mathrm{~V} / \mathrm{Pa}$. The microphone was housed with an aluminum shell for protecting against welding spatter; its interior was lagged with anti-wind sponge. Studies in psychoacoustic have demonstrated that when the welding arc sound does not exceed $400 \mathrm{~ms}$ of delay in comparison with the arc voltage signal, the sound will be a reliable indicator of the welding arc behavior [25]. Following these considerations, in this work the microphone was positioned at $200 \mathrm{~mm}$ from the welding arc. The pyrometer is housed inside a stainless steel shield, its measuring output signal is the standard loop current $4-20 \mathrm{~mA}$., which is proportional to monitored temperature. This sensor was located at $600 \mathrm{~mm}$. from welding pool following its technical recommendations.

Virtual instrumentation software, energy source, data acquisition card, and control equipment set up as shown in the Fig. 6 was used for acquisition and processing data based on the voltage, current, sound and infrared signals. These signals were sampled at $20 \mathrm{kHz}$. The welding experiments were performed in bead on plate position on steel plates AISI $1020(30 \mathrm{~mm} \mathrm{x}$ $200 \times 6.50 \mathrm{~mm}$ ), electrode wire 410NiMo MC with $1.2 \mathrm{~mm}$ of diameter, shield gas was mixture of argon and carbonic anhydride C 25 ( $\mathrm{Ar} 75 \%+\mathrm{CO} 225 \%$ ), holding as constants the CTWD at $10 \mathrm{~mm}$. and the shield gas flux at $15 \mathrm{l} / \mathrm{min}$.

The welding experiments were performed setting three welding speed levels $(7,9,11-\mathrm{mm} / \mathrm{s})$, four arc voltage levels $(18,19,20,21-\mathrm{V})$ and five wire feed speeds levels $(3,3.5,4$, $4.5,5-\mathrm{m} / \mathrm{min}$ ); they were statistical combined.

In spectrometry, all the experiments setup were conducted using a gas tungsten arc welding (GTAW) bead on a plate. The plates used were SAE $10206.35 \mathrm{~mm}$ thick $30 \mathrm{~cm} \times 20 \mathrm{~cm}$ in size. Other important parameters for the experiments are: Welding Speed (Positioning Table), $2.5 \mathrm{~mm} / \mathrm{s}$; Shielding Gas, Argon 10 L/min; Current, 90 A DC; Electrode, Negative EWTh2, $1.6 \mathrm{~mm}$; Stand-Off, $5 \mathrm{~mm}$.

\section{Results and discussions}

In data fusion theory, there are three principal architecture topologies that are categorized according to the type of sensor configurations. They are: complementary, competitive and cooperative types. According the application of the present work, the competitive topology will be used (see Figure 7). In this type 


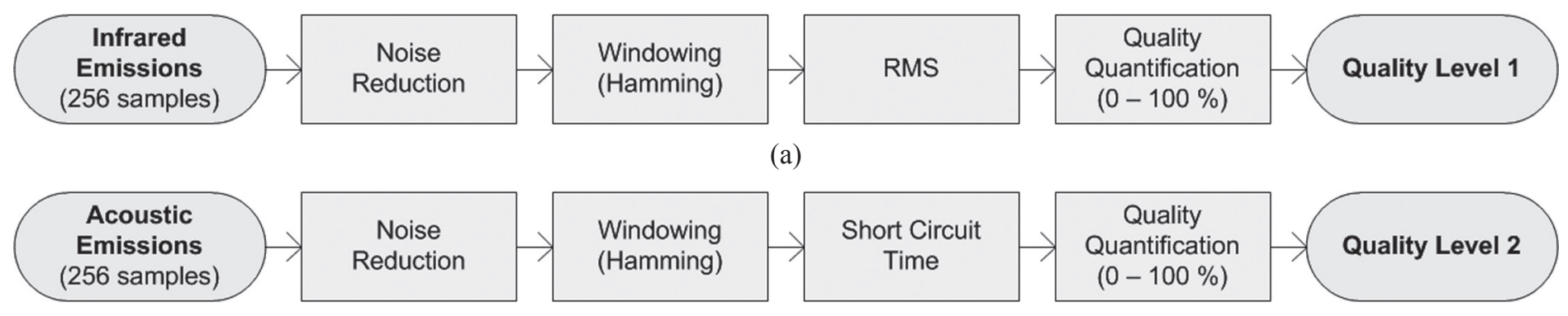

(b)

Figure 8. Pre-processing data signal stages, (a) infrared signal, (b) acoustical signal.

of configuration, each sensor (acoustic and electromagnetic) delivers independent measurements of the same attribute or feature (welding arc behavior).

By pre-processing of information delivered from each sensor, quality level measures are obtained. These measures indicate the quality level from $0 \%$ to $100 \%$, corresponding $0 \%$ to lowest quality as well as $100 \%$ to the best. Figure 8 shows the different pre-processing stages applied at each signal sensor. Data signal segments of 256 samples are pre-processed with a overlapping of $75 \%$; a noise reduction stage is performed, before hamming windowing. In the case of infrared emission signals, the root mean square - RMS was extracted for each data window, with this result, the welding quality quantification stage was carried out. In the case of the acoustic signals, the short circuit time measured and assessed by the quality quantification stage.

In the Figures 9(a) and 9(b) are shown the pre-processing resultant parameters for a welding experiment with an induced perturbation on the weld pool path (ferric chloride) as is shown in the Figure 9(c). By just looking the quality level 1 waveform (see Figure 9(a)), the perturbation interference is imperceptible, but when the quality level 2 is observed, it is possible to note some sudden variations at the presence of the induced perturbation. Hence, which of the two quality level parameters is more

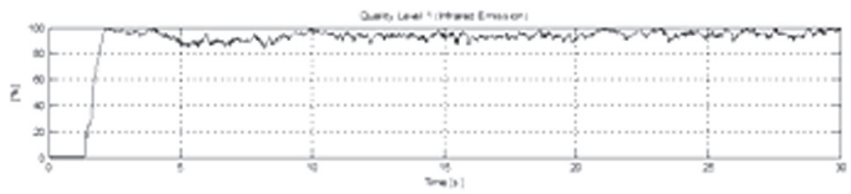

(a)

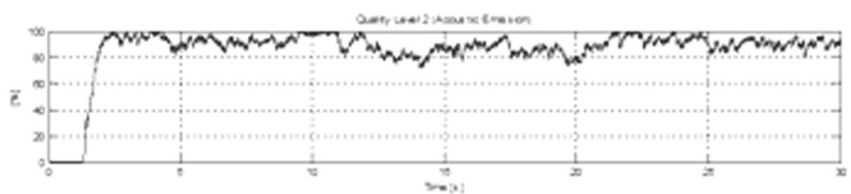

(b)

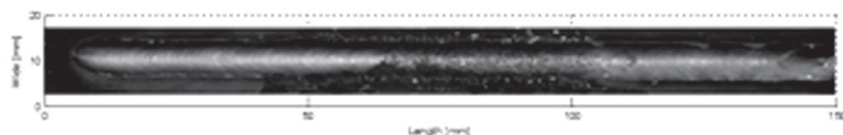

(c)

Figure 9. Quality level parameters, (a) From infrared signal, (b) From acoustical signal, (c) welding trial with induced perturbation. accurately and reliable for assessing the welding quality? A data fusion process could give a more exactly response considering variations and perturbations detected by each sensor.

Figures from 10 to 12 show the fuzzy assessment performance for welding experiments with induced disturbances: variation of arc length (disturbance 1), grease presence (disturbance 2) and absence of gas (disturbance 3 ) respectively. In those can be noted that for the three cases, the stability level has an expressive variation when the welding pool pass through the induced disturbances region. The stability level drops to $0 \%$ in all cases. In steady sate and without perturbations the stability level varies around approximately $90 \%$. In effect, reaching $100 \%$ of stability is a theoretical concept.
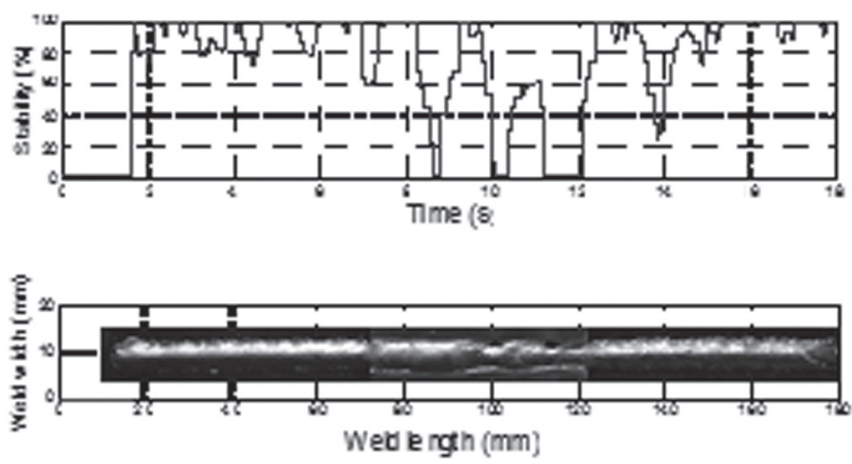

Figure 10. Level of stability in presence disturbances 1.
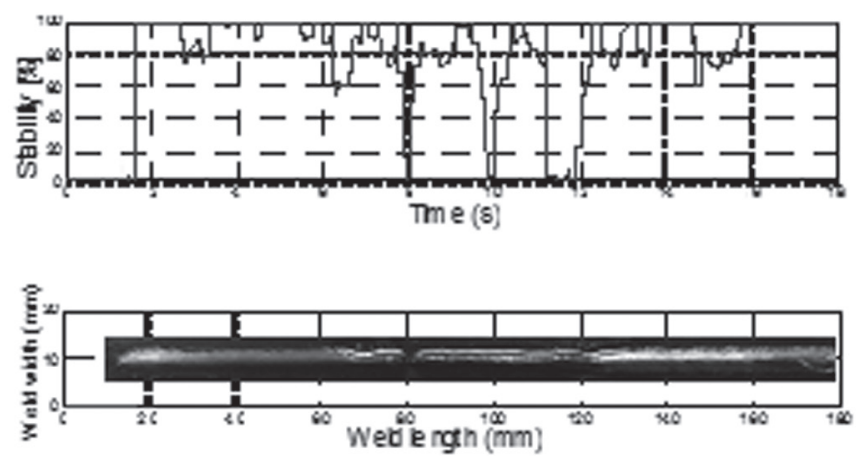

Figure 11. Level of stability in presence of disturbances 2. 


\section{Sensors for Quality Control in Welding}
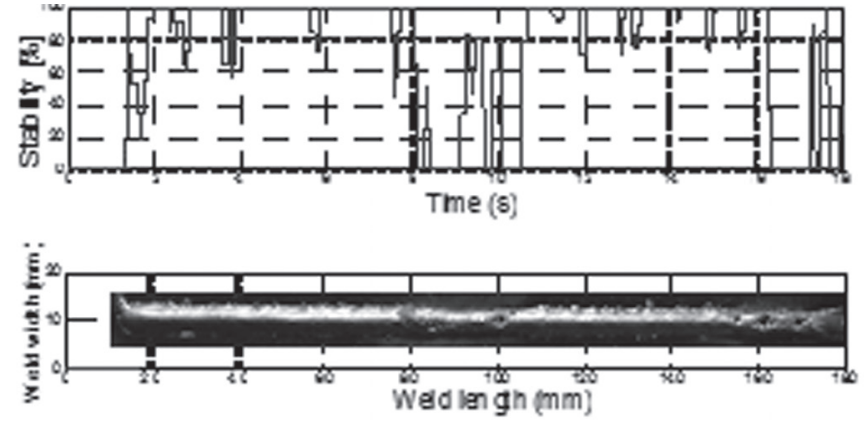

Figure 12. Level of stability in presence of disturbances 3.

By visual inspection of the welding experiments and contrasting the stability waveforms, could be consider two situations of explicit instability. In first place when the magnitude of amplitude variations is too considerable high (more than $60 \%$ ), it is clear that when the amplitude variation increases, the presence of instabilities is more probable. In second place, the instability time duration should be considerate. If the stability level amplitude is less than $60 \%$ and that value remains during long time, definitely there is some welding disturbance. If the stability level reaches $100 \%$, absolutely there is a considerable welding disturbance, what implies a meticulous inspection in the detected area.

An experiment with metallic and sand inclusions is presented in Figure 13. The algorithm for defect detection was Cusum $\mathrm{LS}_{2}$ Filter with $\sigma=0.5$ and $h=5$. The values are arbitrary and they are set to result in fewer errors, like false detection or lack of detection. One can notice in the first graph the reading of the sensor and the result of the filter. The signal was normalized once the interest of the study is the signal fluctuations, not its absolute value. The spectral line chosen was Iron $487.8 \mathrm{~nm}$. Welding parameters were current $90 \mathrm{~A}$, standoff $7 \mathrm{~mm}$, welding speed of $2.5 \mathrm{~mm} / \mathrm{s}$ and gas flow rate $10 \mathrm{~L} / \mathrm{min}$.

It had detected the four metallic inclusions with a great fluctuation due to the increase of Iron at the arc region. There is a disturbance where the sand was included (last defect). There was no increase of Iron because the sand has not this chemical
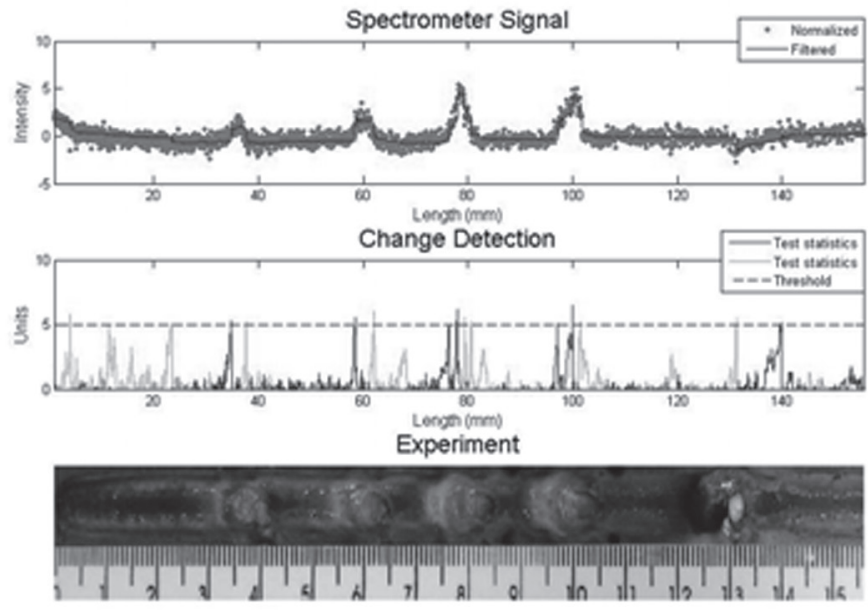

Figure 13. Experiment with metallic and sand inclusions analysis with Cusum LS Filter. element in its composition. But the sand caused interference in the electric arc reflected as a fluctuation of all spectral lines.

\section{Conclusions}

In the present work a quality assessment system based on monitoring of arc welding emission and data fusion was performed. The data fusion process has shown positive results detecting induced perturbations throughout path of the welding pool in comparison at quality assessment method based in single sensoring. By using data fusion of quality levels, the capability and sensitive of the overall quality assessment system is improved. Modeling the quality levels as time series, becomes the quality assessment system is dependent on some constants that are usually obtained experimentally, which makes the assessment system unreliable. This limitation has relation with the lack of relationships between welding quality model and the welding parameters; therefore to perform a welding quality model according welding parameters is necessary.

By monitoring arc welding emission was possible to detect induced perturbation on the welding pool path. Some perturbations are detected by the acoustic emissions and not by infrared emission and in other cases it was noticed contrary situations. Acoustic monitoring was sensitive at environment noise and the quality level extracted from it, has high ripple than the quality level sensed through infrared emissions. Although this discouraging situation, acoustic monitoring could have application in welding process in where the arc is not visible and the optical sensor could not sense any electromagnetic emission. Sensoring based in data fusion improves the monitoring of the welding quality and it could be an alternative against the classical on line methods of assessment and inspection used for detecting and finding disturbances that are based in direct measuring of parameters as arc voltage, welding current, wire feed speed, and others.

The fuzzy logic allowed to quantize the knowledge and experience in welding and became it possible performing a system that can be used in monitoring of stability in welding. Certainly a high acoustic stability coming from welding process indicates a high stability in metal transference. But although the acoustic and the metal transference reach a high stability, that state is not enough condition to catalog a welding process such as high quality.

\section{Acknowledgments}

This work was performed under the auspices of Brazilian Research Councils (CNPq and Capes) and sponsored by the University of Brasilia.

\section{References}

[1] Chen, W.; Chin, B.A. Monitoring Joint Penetration Using Infrared Sensing Techniques. Weld J. 1990, 69, 181s-185s.

[2] Kerr, H.W.; Hellina, M.C.; Huissoon, J.P. Identifying Welding Pool Dynamics for GMA fillet welds. Scien. Tech. Weld. Join. 1999, 4, 15-20. 
[3] Luo, H.K.; Lawrence, F.M.K.; Mohanamurthy, P.H.; Devanathan, R.; Chen, X.Q.; Chan, S.P. Vision Based GTA Weld Pool Sensing and Control Using Neurofuzzy Logic; SIMTech Technical Report AT/00/011/AMP; Automated Material Processing Group: Singapore Institute of Manufacturing Technology, Singapore, 2000, 1-7.

[4] Mirapeix, J.; Cobo, A.; Conde, O.M.; Jaúregui, C.; LópezHiguera, J. M. Real-time arc welding defect detection technique by means of plasma spectrum optical analysis. NDT\&E Int. 2006, 39, 356-360.

[5] Fortunko, C.M. Ultrasonic Detection and Sizing of TwoDimensional Weld Defects in the Long-Wavelength Limit. Ultrason. Symp. 1980, 862-867.

[6] Liu, Y.; Li, X.H.; Ren, D.H.; Ye, S.H.; Wang, B.G.; Sun, J. Computer vision application for weld defect detection and evaluation, Automated Optical Inspection for Industry. Theory Technol. Appl. II. 1998, 3558, 354-357.

[7] Grad, L., J. Grum, I. Polajnar, J. Slabe, "Feasibility study of acoustic signals for on-line monitoring in short circuit gas metal arc welding", International Journal of Machine Tools and Manufacture Volume 44, Issue 5, April 2004, Pages 555-561.

[8] Drouet, M.; Nadeau, F. Acoustic measurement of the arc voltage applicable to arc welding and arc furnaces Phys J. 1982, $15,268 \mathrm{~s}-269 \mathrm{~s}$.

[9] Mansoor, A., J. Huissoon, "Acoustic Identification of the GMAW Process", 9th Intl. Conf. on Computer Technology in Welding, Detroit, USA, 1999, Pages 312-323.

[10] Yaowen, W., Z. Pendsheng, "Plasma-arc welding Sound Signature for on-line Quality Control”, Materials Science \& Engineering Department, Taiyuan University of Technology, Taiyuan 030024, China, 2000, Pages 164-167.

[11] Tam, J. Methods of Characterizing Gas-Metal Arc Welding Acoustics for Process Automation Master Dissertation in Mechanical Engineering, University of Waterloo, CA, 2005.

[12] Poopat, B., E. Warinsiriruk, "Acoustic signal analysis for classification of transfer mode in GMAW by noncontact sensing technique", Journal of Science and Technology, University of Technology Thonburi, Thungkru, Bangmod, 2006, Bangkok, Thailand, Vol. 28, Issue 4, Pages 829-840.

[13] Cayo, E., S. Alfaro, "Welding Quality Measurement Based On Acoustic Sensing”, COBEM-2007, Brasília. 19th International Congress of Mechanical Engineering. São Paulo : ABCM, 2007. v. 1. Pages 2200.

[14] Cayo, E. H. Monitoring, Detection and Localization System for Welding Defects based on the Acoustic Pressure Electric Arc of the GMAW-S Process Master Dissertation in Mechatronics Systems, FT University of Brasilia, DF, Brazil, 2008.

[15] Cayo, E., S. Alfaro, "GMAW process stability evaluation through acoustic emission by time and frequency domain analysis", AMME' 2009, June 2009, Gliwice, Poland, 2009, Pages 157 - 164 .

[16] Lacroix, D., C. Boudot, G. Jeandel, "Spectroscopy Studies of GTA Welding Plasmas. Temperature Calculation and Dilution Measurement". Euro Physics Journal, AP 8, 1999, Pages 61-69. [17] Alfaro, S., D. Mendonça, M. Matos, "Emission Spectrometry evaluation in arc welding monitoring system", Journal of Materials Processing Technology, No. 179, 2006,
Pages 219-234.

[18] Mirapeix, J., A. Cobo, D. González, J. López-Higuera, "Plasma spectroscopy analysis technique based on optimization algorithms and spectral synthesis for arc-welding quality assurance". Optics Express, Vol. 5, no. 4, 2007, Pages 18841889.

[19] Nagarajan, S., P. Banerjee, W. Chen, B. Chin, "Control of the Process Using Infrared Sensors", IEEE Transaction on Robotics and Automation, Vol. 8, no. 1, 1992, Pages 86-93. [20] Wikle III, H.C. Kottilingam. S.; Zee, R.H.; Chin, B.A. Infrared Sensing Techniques for Penetration Depth Control of the Submerged Arc Welding Process. J. Mater. Process. Technol. 2001, 113, 228-233.

[21] Fan, H., N. Ravala, H. Wikle III, B. Chin, "Low-cost infrared sensing system for monitoring the welding". Journal of Materials Processing Technology, no. 140, 2003, Pages 668-675. [22] Alfaro, S., P. Drews, "Intelligent Systems for Welding Process Automation", Journal of the Brazilian Society of Mechanical Sciences, Vol. 28, No. 1, 2006, Pages 25-29.

[23] Marotta, A. (1994), "Determination of axial thermal plasma temperatures without Abel inversion", Journal of Physics D. Applied Physics, 27, 268-272.

[24] NIST, National Institute of Standards and Technology (accessed in may 2010) http://physics.nist.gov/PhysRefData/ ASD/lines form.html

[25] Tam, J.; Huissoon, J. Developing Psycho-Acoustic Experiments in Gas Metal Arc Welding. In International Conference on Mechatronics \& Automation, Niagara Falls, ON, Canada, July 2005, pp. 1112-1117

[26] Drouet, M.; Nadeau, F. Pressure waves due to Arcing Faults in a Substation, IEEE Transactions on Power Apparatus and Systems 1979, 5, 98s.

[27] Hermans, M.J.M.; Den O.G. Process behavior and stability in short circuit gas metal arc welding. Weld. J. 1999, 78, $137 \mathrm{~s}-141 \mathrm{~s}$

[28] Bingul, Z.; Cook, G.E. Dynamic modeling of GMAW process. In 1999 IEEE International Conference on Robotics and Automation, 4, 3059s-3064s.

[29] Adolfsson, S.; Bahrami, A.; Bolmsjö, G.; Claesson, I. Online quality monitoring in short-circuit gas metal arc welding. Weld. J. 1999, 78, 59s-73s.

[30] Naidu, D.S.; Ozcelik, S.; Moore, K.L. Modeling, Sensing and Control of Gas Metal Arc Welding, 1st ed. Elsevier Science Ltd. Kidlington, Oxford OX5 1GB, UK, 2003, 373p. 